\title{
Mortality among involuntary inpatients of psychiatric hospital
}

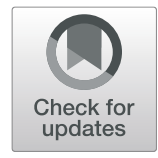

Iuliu Fulga, Anca-lulia Neagu, Marius Neagu* (D) and Ana Fulga

\begin{abstract}
Background: Mortality is often used as an indicator of public health efforts. Even if mortality in psychiatric hospitals decreased since the introduction of modern treatment, the death toll is still high. The authors have analyzed the forensic autopsy data and the medical documentation regarding 115 death cases from psychiatric hospitals in south-eastern Romania during the period of 2000-2020.

Results: The average annual mortality rate was $5.13 \%$, the necropsy data corroborated with those from the medical documentary material indicates acute myocardial infarction as the dominant cause, with 65 (56.5\%) cases, followed by upper respiratory tract occlusion with 23 cases (20\%) and pulmonary thromboembolism in 4 cases (12.2\%). Furthermore, in 6 cases (5.2\%) the cause of death was traumatic: 4 cases of cranio-cerebral trauma and 2 cases of hanging.

Conclusions: In the mortality structure of psychiatric patients, cardiac death predominated, being influenced by the cardiotoxic effect of medication administered for the specific pathology; hence, an early involvement of cardiologists in the follow-up of patients and the finding of treatment schemes with a reduced cardiotoxic effect are required.
\end{abstract}

Keywords: Psychiatry, In-hospital death, Autopsy

\section{Background}

In psychiatric epidemiology, death is one of the important data points, which can be used more precisely for both research and service planning. High mortality rates among individuals with mental illness have been reported in various studies, but very little focus has been placed on the cause of death (Colton and Manderscheid 2006). Mortality in psychiatric patients both from natural and non-natural causes was reported to be markedly higher than in the general population (D'Avanzo et al. 2003).

The hypotheses about why people with psychiatric disorders are more likely to die than the rest of the population are numerous, with different points of view which are often based on data that could be contradictory from one point of view to another. The analysis of in-hospital

\footnotetext{
* Correspondence: mariusneagu87@gmail.com

Faculty of Medicine and Pharmacy, Dunarea de Jos University of Galati, 35 Cuza St., 800010 Galati, Romania
}

\section{Springer Open}

(c) The Author(s). 2021 Open Access This article is licensed under a Creative Commons Attribution 4.0 International License, which permits use, sharing, adaptation, distribution and reproduction in any medium or format, as long as you give appropriate credit to the original author(s) and the source, provide a link to the Creative Commons licence, and indicate if changes were made. The images or other third party material in this article are included in the article's Creative Commons licence, unless indicated otherwise in a credit line to the material. If material is not included in the article's Creative Commons licence and your intended use is not permitted by statutory regulation or exceeds the permitted use, you will need to obtain permission directly from the copyright holder. To view a copy of this licence, visit http://creativecommons.org/licenses/by/4.0/. deaths has an important role for clinical audit, maintaining and improving the management quality, therapeutic protocols, and patterns of professional behavior of the medical staff (Grigoletti et al. 2009). This study was undertaken with the objective of assessing mortality and the cause of death among psychiatric inpatients of psychiatric hospitals in south-eastern Romania.

\section{Methods} 列 in the psychiatric hospitals from south-eastern Romania during the period of $2000-2020$. Out of the 195 cases registered in the hospital records during the analyzed period, the police ordered the conduct of forensic autopsy on 115 cases. According to the Romanian legislation, the death in custody (penitentiary, psychiatric hospital) is part of the category of suspicious deaths, the 
investigation by prosecutors and police officers being mandatory. The rest of 80 cases were voluntary hospitalizations in non-psychiatric health units and their death didn't raise any suspicions. The study followed the analysis of the dynamic of lethal cases, causes of death, the hospitalization period, the psychiatric pathology, the non-psychiatric pre-existing conditions, the preventable/ non-preventable character of death, involuntary hospitalizations with an unfortunate evolution towards death, the role in thanatogenesis of the traumatic injuries. In the interest of elaborating some measures regarding the prediction and prophylaxis of in-hospital death, the results were made available to the General Medical Council and the management of the psychiatric hospital.

\section{Results}

The study group included a number of 80 (69.6\%) men and 35 (30.4\%) women, aged between 19 and 74 years old. All patients admitted to the hospital were diagnosed with psychiatric pathology, for which they received specific medication. The medical history also included nonpsychiatric pathologies of heart failure (15 patients,
13\%), chronic obstructive pulmonary disease (5 patients, $4.3 \%$ ), diabetes mellitus (10 patients, $8.6 \%$ ), and hypertension (20 patients, 17.2\%). Regarding the psychiatric pathology, this study found that the majority of involuntarily admitted inpatients were hospitalized with alcoholism (58 patients, 51.3\%), 21 patients, respectively $18.3 \%$ with dementia; 18 patients, respectively $15.7 \%$ with schizophrenia; 12 patients, respectively $10.4 \%$ with depression; and the rest with various pathology.

Table 1 shows the results of this study, correlating the cause of death with gender, mean age, mean hospitalization period, psychiatric pathology, the preventable/non-preventable character of death, and the presence of traumatic injuries.

\section{Discussions}

The average annual mortality rate was $5.13 \%$, being higher than the values regarding the incidence of emergency in-hospital death in Romania, as Vladescu et al. found that among all patients admitted in hospital, between 2.8\% (in 2014) and 4.1\% (in 2019) died during hospitalization (Vladescu et al. 2019). For a majority of

Table 1 Data regarding the deceased inpatients of the psychiatric hospital in the study period

\begin{tabular}{|c|c|c|c|c|c|c|c|c|c|c|c|c|}
\hline \multirow[t]{2}{*}{ Cause of death } & & \multicolumn{2}{|c|}{ Gender } & \multicolumn{5}{|c|}{ Psychiatric pathology } & \multirow[t]{2}{*}{ Age } & \multirow{2}{*}{$\begin{array}{l}\text { Hospitalization } \\
\text { duration }\end{array}$} & \multirow{2}{*}{$\begin{array}{l}\text { Preventable/ } \\
\text { non- } \\
\text { preventable }\end{array}$} & \multirow{2}{*}{$\begin{array}{l}\text { Traumatic } \\
\text { injuries }\end{array}$} \\
\hline & & $\bar{M}$ & $F$ & Alcohol & Dementia & Schizoph & Depress & Other & & & & \\
\hline \multirow{2}{*}{$\begin{array}{l}\text { Acute myocardial } \\
\text { infarction } \\
\text { No cases = } 65 \\
(56.5 \%)\end{array}$} & $\begin{array}{l}\% \\
\text { death } \\
\text { cause }\end{array}$ & $78.5 \%$ & $21.5 \%$ & $46.2 \%$ & $32.3 \%$ & $6.2 \%$ & $12.3 \%$ & $3 \%$ & \multirow[t]{2}{*}{$\begin{array}{l}63.5 \\
\text { years }\end{array}$} & \multirow[t]{2}{*}{5 days } & \multirow[t]{2}{*}{-} & \multirow[t]{2}{*}{-} \\
\hline & $\begin{array}{l}\% \text { all } \\
\text { cases }\end{array}$ & $44.3 \%$ & $12.2 \%$ & $26.1 \%$ & $18.3 \%$ & $3.5 \%$ & $6.9 \%$ & $1.7 \%$ & & & & \\
\hline \multirow{2}{*}{$\begin{array}{l}\text { Upper respiratory } \\
\text { tract obstruction } \\
\text { No cases }=23 \\
(20 \%)\end{array}$} & $\begin{array}{l}\% \\
\text { death } \\
\text { cause }\end{array}$ & $73.9 \%$ & $26.1 \%$ & $43.5 \%$ & $21.7 \%$ & $13 \%$ & $17.4 \%$ & $4.4 \%$ & \multirow[t]{2}{*}{$\begin{array}{l}58.3 \\
\text { years }\end{array}$} & \multirow[t]{2}{*}{2 days } & \multirow[t]{2}{*}{$+/-$} & \multirow[t]{2}{*}{+} \\
\hline & $\begin{array}{l}\% \text { all } \\
\text { cases }\end{array}$ & $14.8 \%$ & $5.2 \%$ & $8.6 \%$ & $4.4 \%$ & $2.6 \%$ & $3.5 \%$ & $0.9 \%$ & & & & \\
\hline \multirow{2}{*}{$\begin{array}{l}\text { Pulmonary } \\
\text { thromboembolism } \\
\text { No cases = } 14 \\
(12.2 \%)\end{array}$} & $\begin{array}{l}\% \\
\text { death } \\
\text { cause }\end{array}$ & $64.3 \%$ & $35.7 \%$ & $14.3 \%$ & $35.7 \%$ & $21.4 \%$ & $14.3 \%$ & $14.3 \%$ & \multirow[t]{2}{*}{$\begin{array}{l}49.2 \\
\text { years }\end{array}$} & \multirow[t]{2}{*}{6 days } & \multirow[t]{2}{*}{-} & \multirow[t]{2}{*}{+} \\
\hline & $\begin{array}{l}\% \text { all } \\
\text { cases }\end{array}$ & $7.8 \%$ & $4.4 \%$ & $1.7 \%$ & $4.4 \%$ & $2.6 \%$ & $1.7 \%$ & $1.7 \%$ & & & & \\
\hline \multirow{2}{*}{$\begin{array}{l}\text { Cranio-cerebral } \\
\text { trauma } \\
\text { No cases }=4 \\
(3.5 \%)\end{array}$} & $\begin{array}{l}\% \\
\text { death } \\
\text { cause }\end{array}$ & $75 \%$ & $25 \%$ & $50 \%$ & $25 \%$ & $25 \%$ & / & / & \multirow[t]{2}{*}{$\begin{array}{l}41.5 \\
\text { years }\end{array}$} & \multirow[t]{2}{*}{1 day } & \multirow[t]{2}{*}{+} & \multirow[t]{2}{*}{+} \\
\hline & $\begin{array}{l}\% \text { all } \\
\text { cases }\end{array}$ & $2.6 \%$ & $0.9 \%$ & $1.7 \%$ & $0.9 \%$ & $0.9 \%$ & / & / & & & & \\
\hline \multirow[t]{2}{*}{$\begin{array}{l}\text { Hanging } \\
\text { No cases = } 2 \\
(1.7 \%)\end{array}$} & $\begin{array}{l}\% \\
\text { death } \\
\text { cause }\end{array}$ & $100 \%$ & / & $50 \%$ & / & / & $50 \%$ & / & \multirow[t]{2}{*}{$\begin{array}{l}36.5 \\
\text { years }\end{array}$} & \multirow[t]{2}{*}{3 days } & \multirow[t]{2}{*}{+} & \multirow[t]{2}{*}{+} \\
\hline & $\begin{array}{l}\% \text { all } \\
\text { cases }\end{array}$ & $1.7 \%$ & / & $0.9 \%$ & / & / & $0.9 \%$ & / & & & & \\
\hline \multirow[t]{2}{*}{$\begin{array}{l}\text { Other } \\
\text { No cases = } 7 \\
(6.1 \%)\end{array}$} & $\begin{array}{l}\% \\
\text { death } \\
\text { cause }\end{array}$ & $57.1 \%$ & $42.9 \%$ & $28.6 \%$ & $14.3 \%$ & $14.3 \%$ & $28.6 \%$ & $14.3 \%$ & \multirow[t]{2}{*}{$\begin{array}{l}54.6 \\
\text { years }\end{array}$} & \multirow[t]{2}{*}{5 days } & \multirow[t]{2}{*}{-} & - \\
\hline & $\begin{array}{l}\% \text { all } \\
\text { cases }\end{array}$ & $3.5 \%$ & $2.6 \%$ & $1.7 \%$ & $0.9 \%$ & $0.9 \%$ & $1.7 \%$ & $0.9 \%$ & & & & \\
\hline
\end{tabular}


the cases, the death occurred under one week from admission in the hospital. This period is considered crucial for the patients, some of them are starting a new treatment, and others need adjustments, or in some cases, they suffer from abstinence syndrome from drugs or alcohol. The necropsy data corroborated with those from the medical documentary material indicates acute myocardial infarction as the dominant cause, with 65 (56.5\%) cases out of the 115 described. This data is comparable with the results presented in the literature (Waller et al. 1992; Ifteni et al. 2014). Data from the literature (Brown et al. 2000; DeHert et al. 2011) demonstrates that the increased risk of cardiac death of patients with psychiatric pathology is attributed to the cardiotoxic effect of specific medication and decompensation of pre-existing cardiovascular disease. Ifteni et al. (2014) observed that the clinical manifestation of the cardiotoxicity includes myocarditis, cardiomyopathy, and sinus tachycardia. The data from the analyzed documentary material shows that in all these cases, the risk of adverse effects of psychiatric medication was taken into account, by highlighting the cardiovascular pathology, performing the interclinical cardiological examination, and following the recommendations. Thus, even if all these cases are part of the nonpreventable category, we advocate for the intervention of the cardiologist since the admission of patients to the hospital, as well as for the administration of medication with diminished cardiotoxic effect.

A number of 23 cases (20\%) died of upper respiratory tract occlusion, being the consequence of swallowing disorders associated with psychiatric pathology. In cases of occlusion of the airways with gastric reflux, the action of extrinsic traumatic factors could not be ascertained. Studies demonstrate the increased risk of dysphagia in psychiatric patients by extrapyramidal syndrome and by bradykinetic dysphagia (Bazemore et al. 1991) and fast eating syndrome (Fioritti et al. 1997).

Our results showed that in 14 cases $(12.2 \%)$ the cause of death was due to pulmonary thromboembolism, the consequence of thrombosis of the pelvic limbs' venous network. Shulman et al. (2013) showed that the administration of antipsychotic drugs poses an increased risk of deep vein thrombosis. The performed toxicological examination did not reveal alcohol or illegal drugs, the qualitative and quantitative results of the medicinal substances found in the blood and urine complied with the limits provided by the therapeutic protocols and the therapeutic doses.

In 72 cases (62.6\%), no signs of action of traumatic factors extrinsic to the body were found. In 37 cases $(32.2 \%)$ of the cases, minor traumatic injuries were found, but due to their location and morphological aspect, they could not explain the death of the patient. In 6 cases $(5.2 \%)$, the cause of death was traumatic, with 4 cases of cranio-cerebral trauma and 2 cases of hanging. All the cases of cranio-cerebral trauma had massive intracranial injuries that were caused by falls due to seizure or syncopal attacks. Struble-Fitzsimmons et al. (2018) found that falls are the most common safety incident among hospitalized patients.

In the hanging cases, death leading self-induced external and internal traumatic injuries were found at the cervical region, without other injuries with significance of an attack-defence action. The in-hospital suicide rate can be reduced by developing strategies to combat the phenomenon, with the application of educational measures for medical staff involved in patient care (Xue et al. 2020; Alexa-Stratulat et al. 2018).

\section{Recommendations for inpatients mortality reduction}

Psychiatric patients often have limited ability to recognize and communicate the symptoms of a physical illness, which is why many of them remain with undiagnosed acute or chronic illnesses, therefore they need a thorough clinical and paraclinical examination after their admission to hospital.

If pre-existing pathologies are found in the initial assessment, depending on their type, a complete and complex examination of a specialist in that pathology is necessary and mandatory. The examination of a specialist is also mandatory when the psychiatric medication is known to have certain organ toxicity. Doing so, the treatment of the psychiatric patient can be individualized (e.g., a patient with cardiac pathology needs a cardiological examination and medication with cardio-toxicity should be used with caution and as a last resort).

The assessment and the following steps described above should be repeated for patients with a long hospitalization and are mandatory if there are any health deteriorations or treatment changes.

Another important step in the inpatients mortality reduction is the assessment of the risk for falls and modifiable risk factors should be addressed before any serious injury. Also, re-assessment should be regularly conducted throughout the admission.

Although the data in the analyzed medical documentation show that the protocols were fully followed, in the case of occlusion of the upper airway, the specific medication given and the level of hospital care were not sufficient to prevent death. Thus, it is necessary to review the care protocols of patients at risk of swallowing disorders, with the subsequent training of staff.

Regarding the prevention of in-hospital suicides, psychiatric hospitals should use instruments for suicide risk assessment, like "Framework for Suicide Risk Assessment and Management for NSW Health Staff" (NSW Department of Health 2004). Suicide risk assessment should be conducted on admission with re-assessment 
throughout the hospitalization, after each assessment a suicide risk level is determined followed by the management of that risk, a good communication being essential for consistent and coordinated care.

\section{Study limitations}

In Romania, there is no database with information regarding inpatient mortality, at the level of hospital units or national sanitary control authorities. This study could represent the first step in establishing these databases which can be proved as a good instrument for clinical audit and would increase the quality of the medical act.

The present study doesn't include cases from chronic psychiatric inpatients, a direction that the authors of this study would like to see in future research, maybe with parallels between the characteristics of acute psychiatric inpatients and the chronic ones.

\section{Conclusion}

In conclusion, the average annual mortality rate in the psychiatric hospitals does not differ from the average values of intrahospital death in Romania. In the mortality structure of psychiatric patients, cardiac death predominated, being favored by the cardiotoxic effect of medication administered for the specific pathology. These data require a prompt response from the medical community, through the review of therapeutic protocols, the early involvement of cardiologists in the follow-up of patients, and the finding of drug treatment schemes with a reduced cardiotoxic effect. Avoiding in-hospital death requires sustained efforts to maintain the level of training of higher, middle, and auxiliary medical staff through continuing education.

\section{Acknowledgements}

The authors are grateful to the Dunarea de Jos University for the library facility support.

\section{Authors' contributions}

All the authors contributed to the study conception and design. IF and MN collected the data. AF conducted the literature research. IF and AIN analyzed and interpreted the data. MN, AIN, and AF have written the manuscript. All authors conducted the critical revision. All authors have read and approved the final manuscript.
Received: 21 January 2021 Accepted: 24 June 2021

Published online: 01 July 2021

\section{References}

Alexa-Stratulat T, Neagu M, Neagu Al, Alexa ID, Ioan BG (2018) Consent for participating in clinicaltrials - is it really informed? Dev World Bioeth 18(3): 299-306. https://doi.org/10.1111/dewb.12199

Bazemore PH, Tonkonogy J, Ananth R (1991) Dysphagia in psychiatric patients: clinical and videofluoroscopic study. Dysphagia 6(1):2-5. https://doi.org/10.1 007/BF02503456

Brown S, Inskip H, Barraclough B (2000) Causes of the excess mortality of schizophrenia. Br J Psychiatry Ment Sci 177(3):212-217. https://doi.org/10.11 92/bjp.177.3.212

Colton CW, Manderscheid RW (2006) Congruencies in increased mortality rates, years of potential life lost, and causes of death among public mental health clients in eight states. Prev Chronic Dis 3:A42

D'Avanzo B, La Vecchia C, Negri E (2003) Mortality in long-stay patients from psychiatric hospitals in Italy-results from the Qualyop project. Soc Psychiatry Psychiatr Epidemiol 38(7):385-389. https://doi.org/10.1007/s00127-003-0646-z

DeHert M, Correll CU, Bobes J, Cetkovich-Bakmas M et al (2011) Physical illness in patients with severe mental disorders. I. Prevalence, impact of medications and disparities in health care. World Psychiatry Off J World Psychiatr Assoc 10(1):52-77. https://doi.org/10.1002/j.2051-5545.2011.tb00014.x

Fioritti A, Giacotto L, Melega V (1997) Choking incidents among psychiatric patients: retrospective analysis of thirty-one cases from West Bologna psychiatric wards. Can J Psychiatr 42(5):515-520. https://doi.org/10.1177/ 070674379704200509

Grigoletti L, Perini G, Rossi A, Biggeri A, Barbui C, Tansella M, Amaddeo F (2009) Mortality and cause of death among psychiatric patients: a 20-year caseregister study in an area with a community-based system of care. Psychol Med 39(11):1875-1884. https://doi.org/10.1017/S0033291709005790

Ifteni P, Correll CU, Burtea V, Kane JM, Manu P (2014) Sudden unexpected death in schizophrenia: autopsy findings in psychiatric inpatients. Schizophr Res 155(1-3):72-76. https://doi.org/10.1016/j.schres.2014.03.011

NSW Department of Health (2004) Framework for suicide risk assessment and management for NSW health staff. NSW Department of Health, Sydney

Shulman M, Njoku IJ, Manu P (2013) Thrombotic complications of treatment with antipsychotic drugs. Minerva Med 104:175-184

Struble-Fitzsimmons D, Oswald A, DiPersia E (2018) Patient location and mobility factors associated with falls on an inpatient geriatric psychiatry unit. Act Adapt Aging 43(4):1-8

Vladescu C, Ciutan M, Musat S (2019) Time trends in inhospital mortality. A retrospective study in Romania 2014-2019. Roman J Legal Med 27(4):399404. https://doi.org/10.4323/rilm.2019.399

Waller BF, Catellier MJ, Clark MA, Hawley DA, Pless JE (1992) Cardiac pathology in 2007 consecutive forensic autopsies. Clin Cardiol 15(10):760-765. https://doi. org/10.1002/clc.4960151014

Xue C, Yang Y, Xu K, Shi X, Liu H (2020) Health personnel-targeted education interventions on inpatient suicide prevention in general hospitals: a scoping review. Int J Nurs Sci 7(4):477-483. https://doi.org/10.1016/j.jinss.2020.09.006

\section{Publisher's Note}

Springer Nature remains neutral with regard to jurisdictional claims in published maps and institutional affiliations.

\section{Funding}

Not applicable.

Availability of data and materials

Not applicable.

\section{Declarations}

Ethics approval and consent to participate

Not applicable.

\section{Consent for publication}

Not applicable. 